\title{
Panorama do Comércio de Madeira Serrada na Microrregião Geográfica de Florianópolis-SC
}

\author{
Adriana da Silva Santos ${ }^{1}$, Flávia Alessandra Pinheiro da Rocha Cordeiro e Silva ${ }^{2}$, \\ Ricardo Augusto Simonetti ${ }^{2}$, Renato Cesar Gonçalves Robert ${ }^{3}$, \\ Alfredo Celso Fantini ${ }^{4}$
}

\begin{abstract}
${ }^{1}$ Eixo Tecnológico de Recursos Naturais, Instituto Federal do Paraná - IFPR, Telêmaco Borba/PR, Brasil ${ }^{2}$ Laboratório de Abastecimento e Mecanização Florestal, Universidade Federal do Paraná - UFPR, Curitiba/PR, Brasil ${ }^{3}$ Departamento de Engenharia e Tecnologia Florestal, Universidade Federal do Paraná - UFPR, Curitiba/PR, Brasil

${ }^{4}$ Departamento de Fitotecnia, Universidade Federal de Santa Catarina - UFSC, Florianópolis/SC, Brasil
\end{abstract}

\begin{abstract}
RESUMO
O presente estudo teve como objetivos diagnosticar e quantificar as principais espécies florestais tropicais e exóticas comercializadas na Microrregião Geográfica de Florianópolis, bem como identificar sua origem e verificar as tendências do comércio de madeira serrada na região. Os dados foram coletados por meio de entrevistas semiestruturadas nos estabelecimentos que comercializam madeira serrada na região. As principais espécies tropicais comercializadas são o angelim e o cambará, enquanto que, entre as espécies exóticas, predominam os gêneros Pinus e Eucalyptus. O consumo mensal foi estimado em $7.000 \mathrm{~m}^{3}$ de madeira serrada, sendo $2.000 \mathrm{~m}^{3}$ de espécies nativas, $3.500 \mathrm{~m}^{3}$ de Pinus e $1.560 \mathrm{~m}^{3}$ de Eucalyptus. O maior percentual de madeira serrada das espécies tropicais provém do Mato Grosso (38\%), enquanto Santa Catarina (95\%) é o principal fornecedor de madeira de Pinus e Eucalyptus.
\end{abstract}

Palavras-chave: comércio madeireiro em Santa Catarina, espécies florestais, fornecimento de madeira.

\section{Lumber Trading in the Florianópolis Region - Santa Catarina, Brazil}

\begin{abstract}
In the present study, we aimed to diagnose and quantify the most important tropical and exotic timber species commercialized in the region of Florianópolis, as well as identify their origin and verify the trends of the lumber market in the area. Data were collected through semistructured interviews with retailers in the region. The main tropical species commercialized are angelim and cambará, while the exotic species are mainly from the genus Pinus and Eucalyptus. The monthly lumber volume commercialized was estimated at $7.000 \mathrm{~m}^{3}$, of which $2.000 \mathrm{~m}^{3}$ were from native species, and $3.500 \mathrm{~m}^{3}$ and $1.560 \mathrm{~m}^{3}$ from Pinus and Eucalyptus species, respectively. The highest percentage of tropical sawnwood species comes from Mato Grosso state (38\%), while Santa Catarina state (95\%) is the main supplier of Pine and Eucalyptus wood.
\end{abstract}

Keywords: timber trade in Santa Catarina, tree species, wood supply. 


\section{INTRODUÇÃO E OBJETIVOS}

O Brasil possui aproximadamente sete milhões de hectares de plantios florestais, dos quais 93,4\% são correspondentes aos gêneros Pinus (25,2\%) e Eucalyptus (74,8\%). Os Estados de Minas Gerais, São Paulo, Paraná, Bahia, Santa Catarina, Mato Grosso do Sul e Rio Grande do Sul se destacam no cenário nacional como os Estados detentores de 87,7\% da área total de plantios florestais, no qual Santa Catarina ocupa o quinto lugar, com cerca de $10 \%$ da área plantada (ABRAF, 2012).

Da área total do território nacional brasileiro, em 2009 estimou-se que aproximadamente 60\% estão cobertos por florestas naturais e $0,8 \%$ por florestas plantadas (SFB, 2010). O Estado do Paraná se destaca como o maior produtor de Pinus no Brasil, enquanto Minas Gerais é responsável pela maior área plantada de Eucalyptus (ABRAF, 2012). Segundo dados do Instituto do Homem e Meio Ambiente da Amazônia (Pereira et al., 2010), dentre os Estados da Amazônia Legal, o Pará é o maior produtor de madeira tropical, seguido por Mato Grosso e Rondônia. De acordo com esses autores, no cenário nacional, a Região Sul ocupa o segundo lugar no que se refere ao consumo interno de madeira tropical, com 15\% do total.

Conforme afirmaram Simioni \& Santos (2004), não há muitas informações referentes ao mercado florestal em Santa Catarina. No caso específico do mercado florestal da Microrregião de Florianópolis, essas informações são ainda mais escassas. Segundo Simioni \& Hoff (2006), a produção florestal e a comercialização da madeira nesse Estado se dão sem um acompanhamento para a geração de banco de dados, resultando na ausência de um planejamento estratégico para o setor.

Nesse contexto, o presente trabalho teve como objetivos diagnosticar e quantificar as principais espécies florestais tropicais e exóticas comercializadas na Microrregião Geográfica de Florianópolis, bem como identificar sua origem e verificar as tendências do comércio de madeira serrada nessa região.

\section{MATERIAL E MÉTODOS}

\subsection{Caracterização da área de estudo}

Oestudofoidesenvolvidojuntoa estabelecimentos responsáveis pelo comércio de madeira serrada na Microrregião Geográfica de Florianópolis (MF), que está situada no litoral de Santa Catarina e é composta pelos municípios de Florianópolis, São José, Biguaçu, Palhoça, Antônio Carlos, Governador Celso Ramos, Paulo Lopes, Santo Amaro da Imperatriz e São Pedro de Alcântara (Figura 1). Sua população, em 2012, foi estimada em 878.260 habitantes pelo Instituto Brasileiro de Geografia e Estatística, destacandose por ser a microrregião mais populosa de Santa Catarina (IPEADATA, 2010).

A Microrregião possui uma área total de $2.489 \mathrm{~km}^{2}$. A economia de seus municípios está alicerçada em prestação de serviços públicos, comércio, turismo, indústria de transformação e agricultura. A maior contribuição da formação do Produto Interno Bruto (PIB) dessa microrregião está associada ao setor terciário da economia, com exceção de Antônio Carlos, onde a indústria é a atividade que contribui com a maior renda do município (IBGE, 2010). Ainda segundo essa fonte, o PIB da Microrregião em 2009 foi de aproximadamente oito milhões de reais, ocupando a segunda posição no ranking estadual, atrás somente da Microrregião de Joinville. Em relação aos demais Estados brasileiros, Santa Catarina se destaca pelas menores taxas de analfabetismo e Índices de Desenvolvimento Humano (IDH) acima da média. Conforme o ranking de IDH dos municípios, o núcleo metropolitano de Florianópolis classifica-se em primeiro lugar, em que o município de Florianópolis se destacou como a capital brasileira de maior IDH do Brasil (PNUD, 2000). Todas essas estatísticas sugerem que existe um grande mercado consumidor, com grande potencial para o comércio de madeira.

\subsection{Coleta e análise de dados}

Os dados foram coletados no período de agosto de 2010 a fevereiro de 2011, por meio de entrevistas semiestruturadas junto aos gerentes e proprietários de estabelecimentos que atuam no comércio de madeira serrada (bruta e beneficiada), 


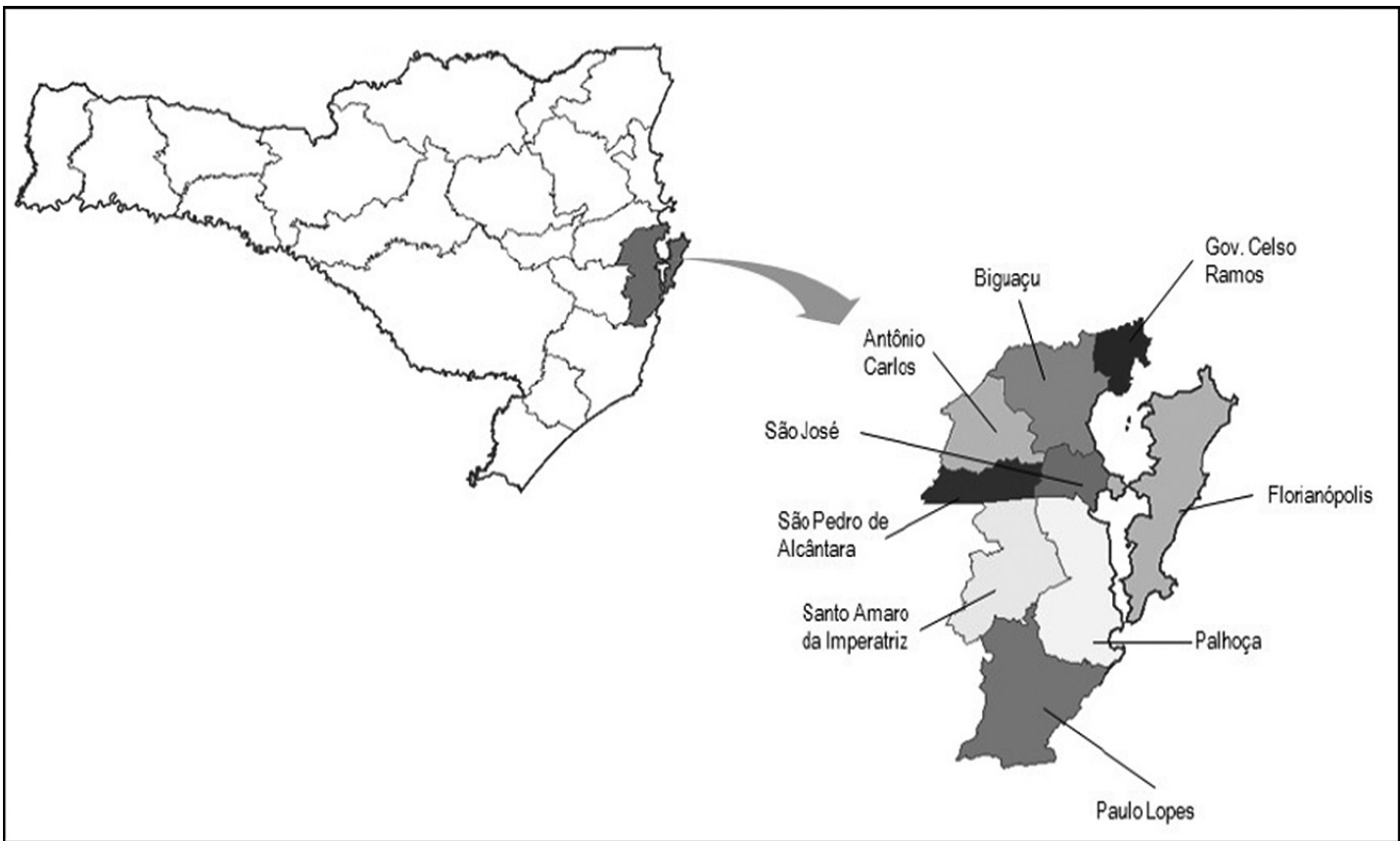

Figura 1. Localização dos municípios que compõem a Microrregião Geográfica de Florianópolis.

Figure 1. Location of the municipalities that compound de political region of Florianópolis.

na região de abrangência do estudo. Nesta pesquisa, foram considerados apenas os estabelecimentos especializados no comércio de madeira, excluindo, dessa forma, os estabelecimentos cujo comércio de madeira é realizado em conjunto com outros materiais de construção.

Para a coleta dos dados, além de uma varredura in loco, foi realizada uma amostragem não probabilística conhecida como 'bola de neve' (snowball), na qual o primeiro estabelecimento foi encontrado ao acaso e os demais foram sendo indicados pelos estabelecimentos já entrevistados (Biernacki \& Waldorf, 1981). Esse procedimento foi repetido em todos os municípios da MF, sendo a coleta de dados finalizada quando as indicações de novos estabelecimentos ou os conteúdos das respostas eram sistematicamente repetidas. $\mathrm{O}$ questionário aplicado foi composto de perguntas abertas e fechadas, abordando temas que caracterizassem quantitativa e qualitativamente o comércio de madeira serrada dessa região. Os principais pontos abordados foram: espécies de madeiras serradas comercializadas (tropicais e exóticas), volume de madeira comercializado, origem da matéria-prima e particularidades do comércio regional.
Os dados obtidos foram analisados por meio de estatística descritiva simples. Foram visitados 119 estabelecimentos madeireiros na Microrregião de Florianópolis, dos quais 11 optaram por não participar da pesquisa, totalizando, assim, 108 entrevistas realizadas.

\section{RESULTADOS E DISCUSSÃO}

\subsection{Principais espécies de madeira comercializadas}

A partir dos dados obtidos nas entrevistas, observou-se que a maioria dos empreendimentos analisados (62\%) trabalha conjuntamente com madeiras de espécies tropicais e exóticas. Cerca de $12 \%$ trabalham somente com madeiras tropicais, enquanto $26 \%$ afirmaram utilizar apenas madeiras de espécies exóticas. Esses dados demonstram uma dinâmica diferente à encontrada por Schuch et al. (2008), que afirmaram que apenas $8 \%$ dos estabelecimentos especializados no comércio de madeira da Grande Florianópolis trabalham com espécies exóticas e tropicais. Segundo Robert et al. 
(2012), tal fato demonstra um avanço das madeiras exóticas no comércio madeireiro da região, que era estabelecido exclusivamente por madeiras tropicais.

Todos os estabelecimentos que trabalham com madeira de espécies nativas afirmaram utilizar apenas espécies provenientes da Região Amazônica, uma vez que, segundo os entrevistados, a exploração comercial de espécies tropicais nativas das florestas do bioma Mata Atlântica atualmente é severamente restrita pela legislação, o que tem inviabilizado seu comércio. Foram identificadas, na região de estudo, 32 espécies tropicais nativas comercializadas
(Tabela 1), conhecidas no comércio local por seus nomes vernaculares. Assim, em certos casos, algumas espécies podem corresponder a mais de uma espécie madeireira, uma vez que os nomes comuns podem variar entre regiões e pessoas, em função da falta de padronização dessa nomenclatura.

Dentre as madeiras tropicais informadas, as mais frequentes foram as espécies de angelim, encontradas em 93\% dos estabelecimentos participantes desta pesquisa, seguidas pelas espécies de cambará, comercializadas em 54\% (Figura 2).

Tabela 1. Espécies tropicais de madeira serrada comercializadas na Microrregião Geográfica de Florianopólis-SC.

Table 1. Timber of tropical species commercialized in the political region of Florianopolis, SC, Brazil.

\section{Nome vernacular}

Nome científico

\section{$\mathbf{N}^{\circ}$ de estabelecimentos}

Andira sp.; Dinizia sp.; Vatairea sp.; Pithecellobium sp.; Hymenolobium sp.

Vatairea sericea Ducke $\quad 2$

Hymenolobium spp. $\quad 57$

Simarouba spp. 3

Vochysia spp.; Qualea spp. $\quad 55$

Erisma sp. 3

Bertholletia excelsa H.B.K 1

Erisma sp. $\quad 24$

Erisma uncinatum Warm.

\begin{tabular}{llc} 
Cedrinho-vermelho & Erisma uncinatum Warm. & 2 \\
\hline Cedrão; Cedro; Cedro-mara; & Hymenolobium spp.; Cedrelinga catenaeformis D. Ducke & 16 \\
Cedro-Alagoano; Cedro-amazonense & Cedrela fissilis Vell & 7 \\
\hline Cedro-rosa & Apuleia spp.; Dipteryx spp. & 2 \\
\hline Cumaru & Cordia goeldiana Huber & 4 \\
\hline Freijó & Apuleia spp. & 24 \\
\hline Garapeira & Apuleia spp.; Enterolobium spp. & 3 \\
\hline Grápia; Tamboriu & Amburana spp.; Commiphora sp.; Bursera sp. & 2 \\
\hline Imburana & Tabebuia spp. & 16 \\
\hline Ipê & Pouteria spp. & 2 \\
\hline Ipê-champagne & Mezilaurus itauba (Meissn.) aub. Ex Mez & 30 \\
Itaúba & Hymenaea courbaril L. & 17 \\
\hline Jatobá & Cordia trichotoma & 5 \\
Louro & Nectandra rubra ( Mez. ) C.K.Allen & 1 \\
\hline Louro-vermelho & Astronium lecointei Ducke & 8 \\
\hline Muiracatiara; maracatiara & Vochysia spp. & 1 \\
\hline Rosinha & Peltogyne spp. & 6 \\
\hline Roxinho & Vatairea spp.; Andira spp.; Bowdichia sp. & 3 \\
\hline Sucupira & Bowdichia sp.; Diplotropis sp. & 1 \\
\hline Sucupira-preta & Martiodendron spp.; Dialium spp. Tamarindus indica L. & 1 \\
\hline Tamarino; tamarindo & Bagassa guianensis Aubl. & 3 \\
\hline Tatajuba & Couratari spp.; Cariniana spp. & 2 \\
\hline Tauari & Couratari sp. & 1 \\
\hline Tauari-branco & Piptadenia suaveolens Miq. & 1 \\
\hline Tiburana; timborana & & \\
\hline
\end{tabular}

Hymenolobium spp.; Cedrelinga catenaeformis D. Ducke 16

Cedrela fissilis Vell

Apuleia spp.; Enterolobium spp.

Tabebuia spp. 16

Mezilaurus itauba (Meissn.) aub. Ex Mez

Hymenaea courbaril L. 17

Peltogyne spp. 6

Vatairea spp.; Andira spp.; Bowdichia sp. 3

Bowdichia sp.; Diplotropis sp.

Martiodendron spp.; Dialium spp. Tamarindus indica L. $\quad 1$

Couratari spp.; Cariniana spp. 2

Couratari sp.
Bagassa guianensis Aubl. 3 
Na Tabela 2, podem ser visualizados os estabelecimentos participantes da pesquisa em cada município, bem como o número de espécies tropicais comercializadas. O município de Florianópolis foi o que apresentou uma maior diversificação de madeiras tropicais, com 21 espécies mencionadas pelos entrevistados, seguido por Palhoça e São José, ambos com 19 espécies de madeira tropical.

No município de Antônio Carlos, identificouse a menor diversificação no comércio de madeiras tropicais, sendo citada apenas uma espécie, o angelim-pedra (Figura 3). Dessa forma, observouse que os municípios que apresentaram uma maior diversidade de madeiras tropicais apresentaram,

Tabela 2. Número de empresas visitadas e diversidade de madeiras tropicais nos municípios da MF.

Table 2. Companies visited and tropical timber diversity in the municipalities in the region of Florianopolis.

\begin{tabular}{lcc} 
Municípios & $\begin{array}{c}\mathbf{N}^{\circ} \text { de empresas } \\
\text { participantes }\end{array}$ & $\begin{array}{c}\mathbf{N}^{\circ} \text { de } \\
\text { espécies }\end{array}$ \\
\hline Florianópolis & 36 & 21 \\
\hline São José & 22 & 19 \\
\hline Biguaçu & 9 & 7 \\
\hline Palhoça & 19 & 19 \\
\hline Antônio Carlos & 4 & 1 \\
\hline Governador Celso & 2 & 4 \\
Ramos & 7 & 7 \\
Paulo Lopes & 8 & $*$ \\
Santo Amaro da & 1 & 4 \\
Imperatriz & São Pedro de Alcântara &
\end{tabular}

*Não foi apresentada espécie em razão dos estabelecimentos não comercializarem espécies tropicais. também, um maior número de estabelecimentos participantes.

Apesar da diversidade de espécies tropicais verificada no presente estudo, os empreendimentos comercializavam de uma a 13 espécies de madeira tropical, sendo que aproximadamente $34 \%$ dos estabelecimentos entrevistados afirmaram trabalhar com apenas duas espécies. Tal fato pode ser considerado preocupante sob a perspectiva de sustentabilidade ambiental, pois gera uma busca maior por poucas espécies nos Planos de Manejo Florestal Sustentáveis, podendo ocasionar uma diminuição da população ao longo do tempo e aumentar o risco de extinção local dessas espécies (Silva, 2002). Contudo, a inserção de novas espécies de madeiras no mercado pode ser considerada um grande desafio, visto que, apesar de existir uma diversidade de espécies na Amazônia brasileira com potencial madeireiro, poucas são conhecidas pelo mercado consumidor, que geralmente busca espécies mais populares e tradicionais.

Dentre as espécies exóticas comercializadas, destacam-se os gêneros Pinus e Eucalyptus, comercializadas por aproximadamente 99\% dos estabelecimentos que trabalham com espécies exóticas. Apenas um estabelecimento, localizado em Sâo José, afirmou trabalhar com o gênero Tectona, utilizando madeira de aproveitamento para fabricação de esquadrias. Dentre os 95 empreendimentos que comercializam espécies exóticas, 94 utilizam Pinus e 73 deles comercializam também Eucalyptus.

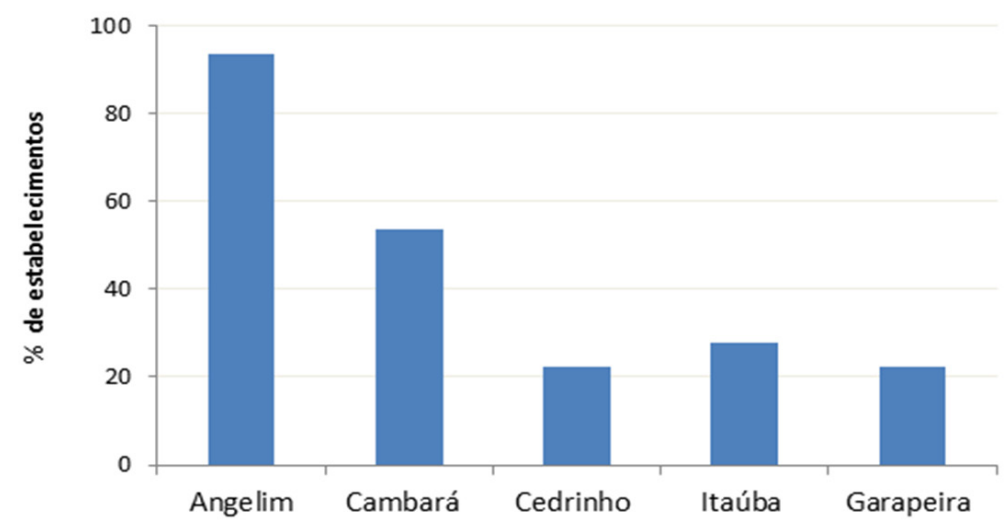

Figura 2. Principais madeiras tropicais comercializadas na Microrregião Geográfica de Florianópolis. Figure 2. Main tropical Woods commercialized in political region of Florianopolis, SC, Brazil. 


\subsection{Volume de madeira serrada comercializado}

Os empreendimentos visitados durante a realização da pesquisa informaram o volume mensal de madeira serrada comercializado de espécies tropicais e exóticas. Dos estabelecimentos que trabalham com madeira tropical, 12,5\% optaram por não informar o volume consumido, enquanto $8,8 \%$ não informaram, alegando não possuir estoque, trabalhando em parceria com outros estabelecimentos da região de acordo com a demanda de madeira solicitada.

De acordo com os dados obtidos, o consumo mensal total estimado de madeira serrada tropical pelos estabelecimentos visitados foi de cerca de $2.000 \mathrm{~m}^{3}$, o que representa, aproximadamente, $38 \mathrm{~m}^{3}$ por estabelecimento. Dessa forma, considerando- se todos os estabelecimentos visitados que comercializam madeira tropical serrada, estima-se que o consumo anual de madeira na Microrregião de Florianópolis seja em torno de $36.000 \mathrm{~m}^{3}$. Conforme pode ser visualizado na Tabela 3, nos estabelecimentos madeireiros avaliados, a maior parte (65\%) informou comercializar volumes inferiores a $60 \mathrm{~m}^{3}$ mensais, sendo essencialmente voltados ao comércio varejista de madeira.

As estimativas de volume das espécies tropicais comercializado mensalmente, por município da MF, podem ser observadas na Figura 4. Analisandose o volume médio mensal por estabelecimento, o município de Biguaçu apresentou a maior média entre os demais municípios, correspondendo a aproximadamente $54 \mathrm{~m}^{3}$. mês ${ }^{-1}$ por estabelecimento, enquanto São José apresentou a segunda maior

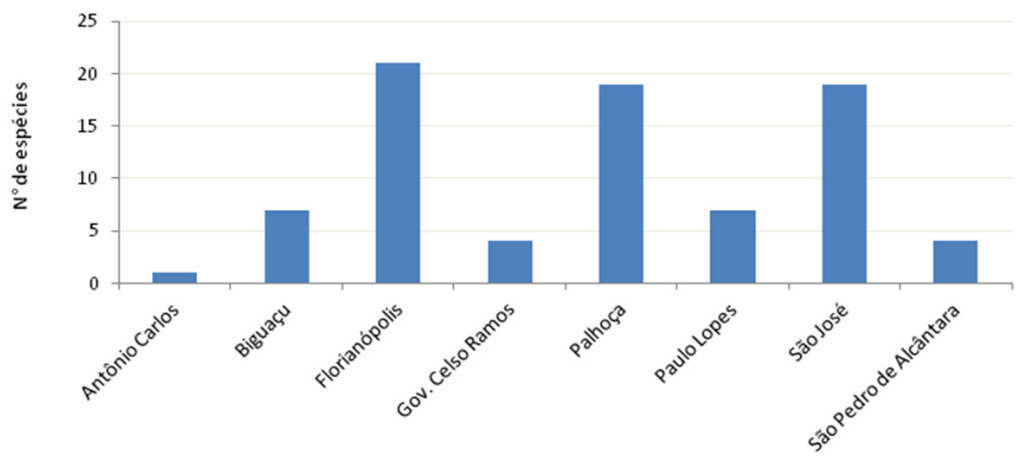

Figura 3. Diversidade de madeiras tropicais observadas nos municípios da Microrregião Geográfica de Florianópolis. Figure 3. Diversity of tropical Woods visualized in the cities of Microregion Geographic of Florianópolis.

Tabela 3. Distribuição percentual de estabelecimentos de acordo com o consumo mensal $\left(\mathrm{m}^{3}\right)$ de madeira serrada de espécies tropicais, Pinus e Eucalyptus.

Table 3. Percentual distribution of establishments according to month consumption (cu.m.) of Pinus and Eucalyptus.

\begin{tabular}{|lccc|}
\hline Volume de madeira serrada & \multicolumn{3}{c|}{ Estabelecimentos na MF (\%) } \\
\hline ( $\left.\mathbf{m}^{\mathbf{3}} \cdot \mathbf{m e ̂ s}^{-1}\right)$ & $\begin{array}{c}\text { Comercializam } \\
\text { Espécies Tropicais }\end{array}$ & $\begin{array}{c}\text { Comercializam } \\
\text { Pinus }\end{array}$ & $\begin{array}{c}\text { Comercializam } \\
\text { Eucalyptus }\end{array}$ \\
\hline $301-60$ & 37,5 & 56,1 & 70,8 \\
\hline $601-90$ & 27,5 & 15,9 & 9,2 \\
\hline $901-120$ & 6,3 & 3,7 & 4,6 \\
\hline $1201-150$ & 5 & 3,7 & 0 \\
$1201-180$ & 0 & 0 & 0 \\
\hline $1801-210$ & 1,3 & 0 & 0 \\
\hline Não possuem estoque & 1,3 & 1,2 & 1,5 \\
\hline Não informaram & 8,8 & 0 & 0 \\
\hline
\end{tabular}




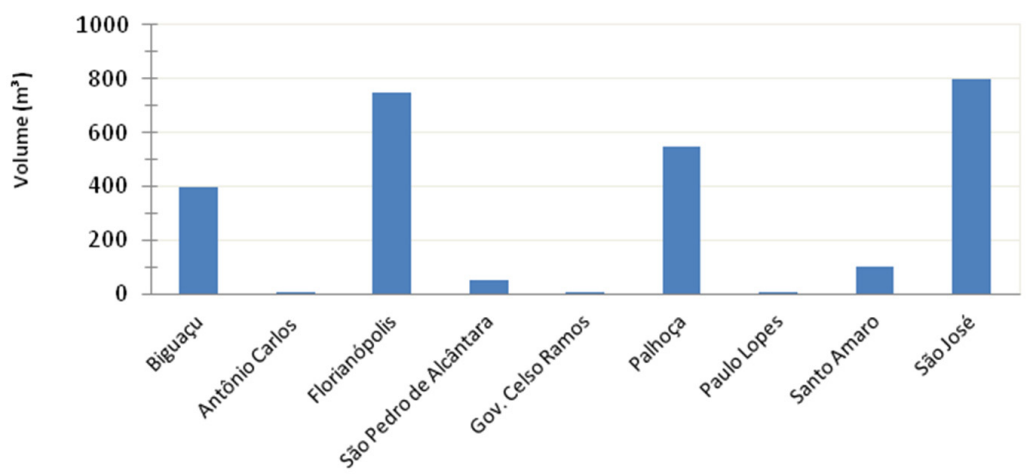

Figura 4. Estimativa dos volumes mensais de madeira serrada tropical, comercializados pelos municípios da Microrregião Geográfica de Florianópolis.

Figure 4. Estimation of month volume of tropical lumber, commercialized in the municipalities of the political region of Florianopolis, SC, Brazil.

média (43 $\mathrm{m}^{3} \cdot \mathrm{mês}^{-1}$ ), seguido por Florianópolis e Palhoça, ambos com aproximadamente $34 \mathrm{~m}^{3}$. $\mathrm{mes}^{-1}$.

Quanto à madeira de espécies exóticas, o volume mensal comercializado pelos estabelecimentos participantes foi de $3.500 \mathrm{~m}^{3}$. $\mathrm{mês}^{-1}$ de Pinus e $1.560 \mathrm{~m}^{3} \cdot \mathrm{mês}^{-1}$ de Eucalyptus, totalizando $60.720 \mathrm{~m}^{3}$. ano $^{-1}$. Dos estabelecimentos avaliados, mais da metade (56\% para Pinus e $71 \%$ para Eucalyptus) comercializa volumes inferiores a $30 \mathrm{~m}^{3} \cdot \mathrm{mês}^{-1}$ de madeira, em ambos os gêneros (Tabela 2). Ao avaliar conjuntamente o comércio de madeiras tropicais e exóticas, o volume mensal observado foi de aproximadamente $7.000 \mathrm{~m}^{3}$. $\mathrm{mes}^{-1}$, dos quais $72 \%$ correspondem às espécies exóticas e $28 \%$ às espécies tropicais. $\mathrm{O}$ percentual de madeira de espécies tropicais encontrado no presente estudo é inferior ao encontrado por Robert et al. (2012), que, ao avaliarem o consumo de madeira serrada no município de Florianópolis, encontraram um percentual de $46 \%$ do volume total proveniente de espécies tropicais. Esse resultado confirma um maior consumo de madeira tropical no município de Florianópolis, que detém o status de ser uma capital de IDH e PIB altos.

De qualquer forma, percebe-se que o volume de madeira de espécies exóticas é maior do que das espécies tropicais, o que indica a utilização crescente das madeiras provenientes de reflorestamento nas serrarias (Vale et al., 2002). Segundo Pereira et al. (2010), a extração de madeira em tora da Amazônia sofreu uma considerável queda nos últimos anos, com redução de 7\% do consumo de madeira da Amazônia na Região Sul, entre 1998 e 2009.

Em função de os entrevistados não informarem o volume de madeira tropical serrada comercializado por espécie, houve um maior detalhamento nos dados referentes ao volume consumido das espécies exóticas. Tal detalhamento tornou possível realizar uma distribuição entre o volume consumido de madeira serrada de Pinus e Eucalyptus sem tratamento químico e de madeira tratada quimicamente, nos distintos municípios da região de abrangência deste estudo (Figura 5).

Observou-se que o município de Paulo Lopes, apesar do pequeno número de estabelecimentos identificados, comercializa volumes consideráveis de madeira serrada do gênero Pinus, apresentando a maior média mensal por estabelecimento das espécies exóticas, correspondente a cerca de $116 \mathrm{~m}^{3}$ por estabelecimento, de Pinus, e $44 \mathrm{~m}^{3}$ por estabelecimento, de Eucalyptus. Esse fato pode ser explicado em razão de boa parte das serrarias participantes (38,5\%) estar localizada nesse município, uma vez que suas serrarias demandam maior quantidade de madeira do que os demais estabelecimentos e são fornecedoras de madeira serrada para certos estabelecimentos da própria MF.

Em relação ao comércio de madeiras tratadas com preservantes químicos, verificou-se que o município de Florianópolis comercializa o maior volume de madeira serrada do gênero Pinus, seguido por Palhoça e São José. Segundo informações dos 


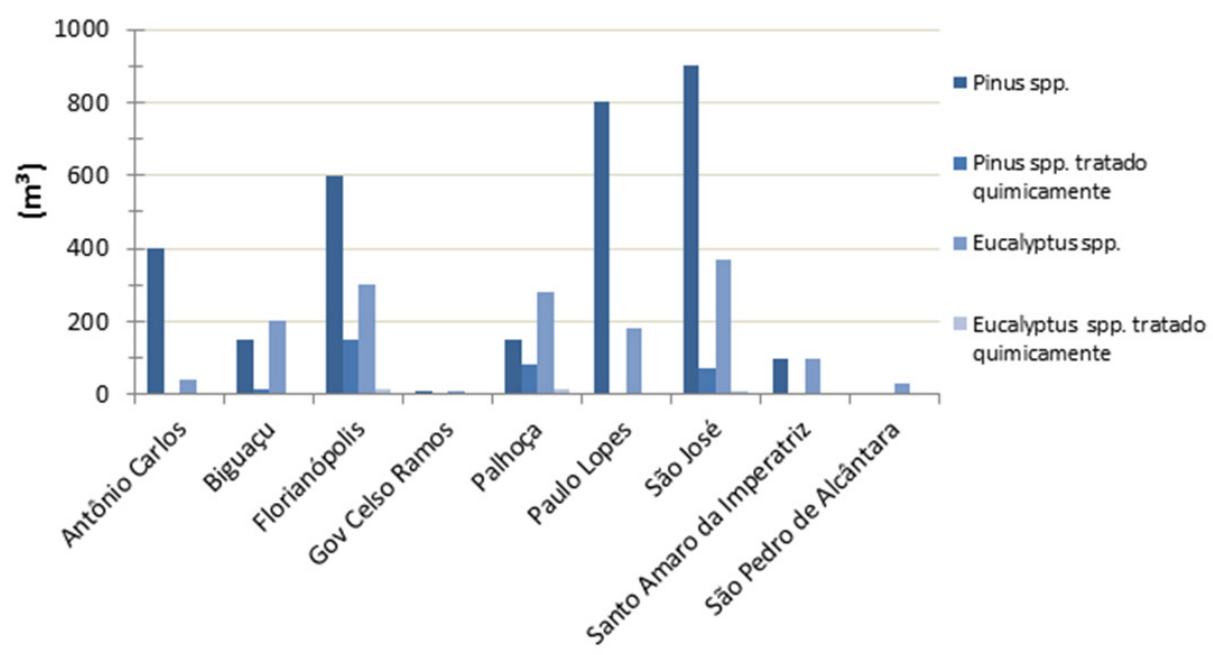

Figura 5. Estimativa de volume de madeira serrada das espécies exóticas comercializadas nos município na Microrregião Geográfica de Florianópolis, SC.

Figure 5. Estimate of the volume of lumber from exotic species commercialized in the political region of Florianopolis, SC, Brazil.

entrevistados, a procura por esse tipo de matériaprima para ser utilizada na construção de decks, píers e pergolados tem sido responsável pela maior parte da sua demanda.

\subsection{Origem da madeira serrada comercializada}

Quanto à origem da madeira serrada de espécies tropicais, foi possível identificar apenas os Estados de origem (Tabela 3). Verificou-se que os empreendimentos participantes da pesquisa recebem madeira de cinco Estados diferentes da Amazônia Legal: Acre, Amazonas, Pará, Rondônia e Mato Grosso. A origem da madeira tropical por estabelecimento variou de um a quatro Estados, embora cerca de $77 \%$ dos comerciantes recebam madeira de apenas um (37\%) ou dois (40\%) Estados.

Conforme demonstrado na Figura 6, dentre os Estados de origem, Mato Grosso aparece como sendo o fornecedor mais mencionado pelos entrevistados (38\%), seguido por Rondônia (29\%). Esses resultados corroboram os encontrados por Pereira et al. (2010), que afirmaram que, no ano de 2009, os Estados de Pará, Mato Grosso e Rondônia foram responsáveis por $91 \%$ do total de madeira em tora extraída na Amazônia Legal.
No que concerne à origem da madeira de pinus e eucalipto, os estabelecimentos avaliados recebem madeira proveniente de 45 municípios de Santa Catarina (92\%) e de quatro (8\%) municípios do Rio Grande do Sul. Esses resultados são similares aos encontrados por Robert et al. (2012), que, ao avaliarem a origem da madeira serrada de pinus e eucalipto exclusivamente no município de Florianópolis, verificaram que $96 \%$ da madeira consumida localmente é proveniente de municípios catarinenses. Na Tabela 4, são apresentados os raios médios de distância entre os estabelecimentos visitados e os fornecedores de matéria-prima aos mesmos.

As maiores distâncias foram observadas quando o estabelecimento trabalha com produtos não autoclavados, visto que um dos fatores inerentes a essa maior distância está na obtenção de produtos com menores custos e diretos de serrarias de primeiro desdobro. As menores distâncias encontradas para os produtos autoclavados estão relacionadas ao fato de que a região possui usinas de tratamento de madeira, fazendo assim com que os estabelecimentos busquem seus produtos nas usinas da região.

A Figura 7 apresenta os municípios fornecedores de madeira dos dois gêneros de espécies exóticas comercializadas, com destaque para os principais municípios fornecedores. A Mesorregião de Grande 


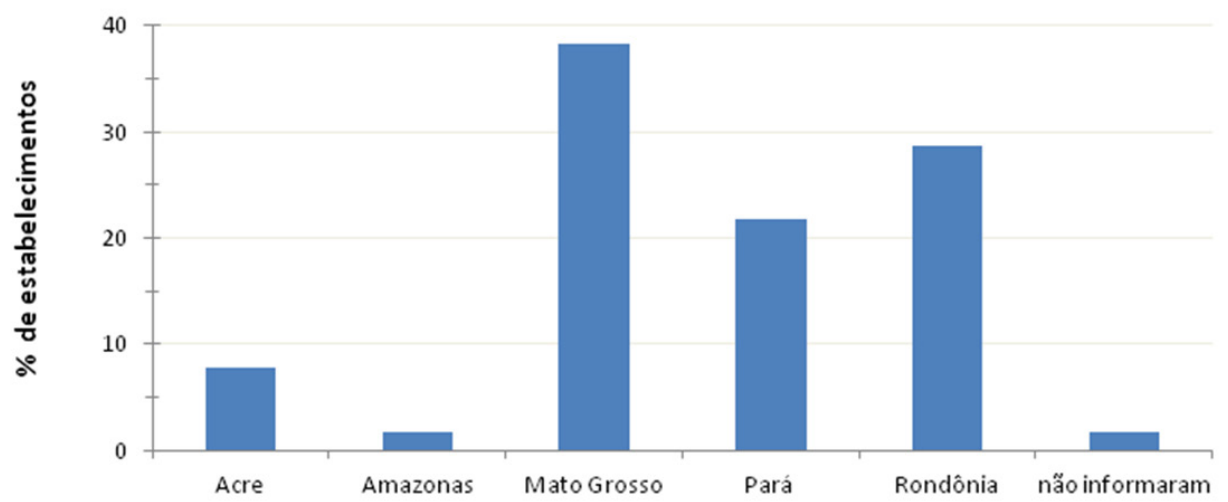

Figura 6. Origem das madeiras de espécies tropicais comercializadas nos municípios na Microrregião Geográfica de Florianópolis-SC.

Figure 6. Origin of tropical timber commercialized in political region of Florianopolis, SC, Brazil.

Tabela 4. Número de estabelecimentos e radio médio de suprimento de madeira de Pinus e Eucalyptus. Table 4. Number of establishments and mean ratio distance of wood suppliers of Pinus and Eucalyptus.

\begin{tabular}{|c|c|c|c|c|c|}
\hline \multirow[b]{2}{*}{ Município } & \multirow{2}{*}{$\begin{array}{c}\text { Número de } \\
\text { Estabelecimentos }\end{array}$} & \multicolumn{4}{|c|}{ Distância Média Dos Fornecedores (Km) } \\
\hline & & $\begin{array}{c}\text { Pinus } \\
\text { Não Autoclavado }\end{array}$ & $\begin{array}{c}\text { Pinus } \\
\text { Autoclavado }\end{array}$ & $\begin{array}{c}\text { Eucalipto } \\
\text { Não Autoclavado }\end{array}$ & $\begin{array}{c}\text { Eucalipto } \\
\text { Autoclavado }\end{array}$ \\
\hline Antonio Carlos & 4 & 215 & 49 & 0 & 0 \\
\hline Biguaçu & 10 & 111 & 47 & 92 & 0 \\
\hline Florianópolis & 39 & 128 & 141 & 133 & 31 \\
\hline $\begin{array}{l}\text { Governador } \\
\text { Celso Ramos }\end{array}$ & 3 & 106 & 30 & 80 & 0 \\
\hline Palhoça & 23 & 93 & 69 & 108 & 118 \\
\hline Paulo Lopes & 8 & 189 & 99 & 118 & 0 \\
\hline São José & 23 & 144 & 65 & 87 & 46 \\
\hline $\begin{array}{l}\text { São Pedro de } \\
\text { Alcântara }\end{array}$ & 1 & 0 & 0 & 0 & 0 \\
\hline $\begin{array}{l}\text { Santo Amaro da } \\
\text { Imperatriz }\end{array}$ & 9 & 122 & 124 & 35 & 64 \\
\hline
\end{tabular}

Florianópolis é a principal fornecedora, com 43,3\% do volume de madeira de Pinus fornecido e $63 \%$ do volume de Eucalyptus abastecido. Os principais municípios fornecedores nos dois gêneros são Florianópolis e Tubarão, com, respectivamente, 31\% e $22,3 \%$ do volume total.

\subsection{Particularidades observadas}

Ao avaliar a percepção dos entrevistados no que se refere à evolução do comércio madeireiro nos últimos cinco anos, $47 \%$ dos participantes afirmaram que houve um crescimento no comércio de madeira serrada no período, enquanto $41 \%$ declararam que perceberam uma redução dessa atividade e 12\% indicaram que o comércio madeireiro permaneceu estável. Dentre os estabelecimentos que alegaram um crescimento no comércio de madeira serrada na região, 21,6\% atribuíram o fato ao baixo preço da madeira serrada originária de reflorestamentos, enquanto $62,7 \%$ o associaram ao crescimento do setor de construção civil, ao aumento da renda familiar e a estímulos financeiros decorrentes de programas de créditos imobiliários. Os principais motivos que levaram os entrevistados a apontar a redução ou a estabilização do comércio desse produto na MF se referem ao elevado preço da madeira serrada de espécies tropicais, à diluição nas vendas em função do aumento do número de estabelecimentos que 


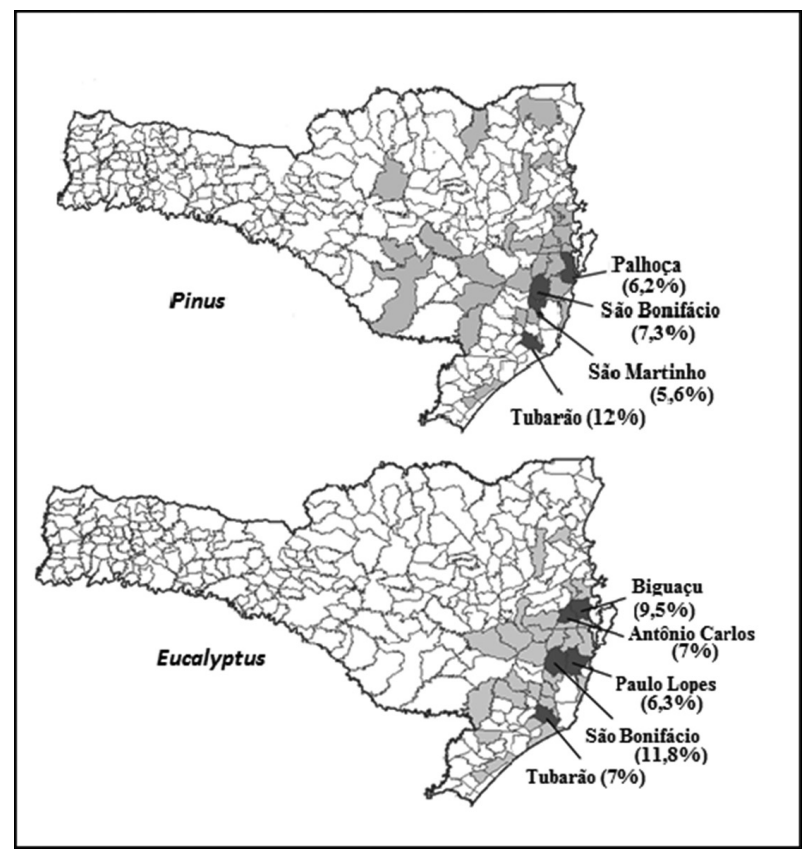

Figura 7. Municípios catarinenses fornecedores de madeira serrada de Pinus e Eucalyptus para os estabelecimentos madeireiros da Microrregião Geográfica de Florianópolis, com destaque aos principais fornecedores.

Figure 7. Municipalities in Catarina state that supply lumber of Pinus and Eucalyptus for retailers in the political region of Florianopolis, SC, Brazil, highlighting the main suppliers.

comercializam madeira serrada na região e à substituição da madeira usada na construção civil por outros materiais, dentre outros.

Quanto às perspectivas futuras para o comércio madeireiro na Microrregião de Florianópolis, os entrevistados não se mostraram muito otimistas, visto que a maioria acredita que haverá redução nas vendas nos próximos anos (38\%) ou a estabilização (23\%). Cerca de $34 \%$ apostam que o comércio madeireiro continuará crescendo, enquanto $5 \%$ dos entrevistados optaram por não se manifestar.

No que se refere aos comerciantes que acreditam no aumento do comércio madeireiro nessa região, cerca de $30 \%$ afirmaram crer que o incremento nos próximos anos, de uma forma geral, ocorrerá em acompanhamento do crescimento do setor de construção civil. Já 16\% não expuseram motivos que justificassem sua opinião, enquanto 54\% apostam no incremento do comércio de madeiras provenientes de reflorestamento, o que, segundo eles, já está ocorrendo atualmente. Não foi evidenciada entre os comerciantes uma tendência segundo a qual fosse possível padronizar as opiniões otimistas a um tipo de comércio (de madeira nativa ou de exóticas).
Dentre os entrevistados, $17 \%$ indicaram que o tratamento com preservantes químicos vem alavancando as vendas das madeiras de reflorestamento, ressaltando que o tratamento químico será um importante fator responsável pela expansão do comércio dessas madeiras, por proporcionar maior durabilidade à madeira $e$ resistência aos insetos.

Observou-se que $16 \%$ dos entrevistados afirmaram encontrar dificuldades para comprar matéria-prima de reflorestamento atualmente e que essa situação tenderá a piorar, visto que as áreas de reflorestamento existentes não atenderão à evolução crescente da demanda, além de as maiores áreas com plantios dessas espécies na região pertencerem às empresas de papel e celulose, que não possuem regularidade na oferta para o setor de madeira serrada. Esse resultado corrobora a afirmação de Bacha (2008), que, ao analisar a evolução do reflorestamento no Brasil, previu que a partir da segunda metade da presente década haverá escassez de madeira e que essa falta afetará mais significativamente empresas sem base florestal própria, como as pequenas serrarias, olarias, fábricas de móveis, etc. 


\section{CONCLUSÕES}

Com base no desenvolvimento do presente estudo e nos resultados e discussões realizadas, pode-se concluir que:

- Na região de estudo, são comercializadas 32 espécies tropicais nativas, das quais as principais são angelim e cambará. Dentre as espécies exóticas comercializadas, destacam-se os gêneros Pinus e Eucalyptus;

- O consumo de madeiras exóticas na região de estudo é mais do que o dobro das madeiras tropicais;

- O principal fornecedor de madeira tropical para a região é Mato Grosso, enquanto Santa Catarina e Rio Grande do Sul são os principais fornecedores de madeira de Pinus e Eucalyptus;

- Segundo a percepção dos empresários entrevistados, existe uma forte tendência à redução do comércio de madeira tropical, podendo haver um incremento na demanda por madeiras de espécies exóticas, em particular das madeiras tratadas quimicamente;

- Parte dos entrevistados afirmou encontrar dificuldades atualmente na compra de matériaprima de reflorestamento e que essa situação tenderá a piorar, uma vez que as atuais áreas de reflorestamento não atenderão à evolução crescente da demanda.

\section{STATUS DA SUBMISSÃO}

Recebido: $02 / 04 / 2013$

Aceito: 03/08/2013

Publicado: 31/02/2014

\section{AUTOR(ES) PARA CORRESPONDÊNCIA}

\section{Adriana da Silva Santos}

Eixo Tecnológico de Recursos Naturais, Instituto Federal do Paraná - IFPR,

Rod. PR 160, Km 19,5, Jardim Bandeirantes, CEP 84269-090, Telêmaco Borba, PR, Brasil e-mail: adriana.silvasantos@ifpr.edu.br

\section{REFERÊNCIAS}

Associação Brasileira de Produtores de Florestas Plantadas - ABRAF. Anuário estatístico da ABRAF 2012 - ano base 2011. Brasília: ABRAF; 2012. 150 p.
Bacha CJC. Análise da evolução do Reflorestamento no Brasil. Revista de Economia Agrícola 2008; 55(2): 5-24.

Biernacki P, Waldorf D. Snowball Sampling: problems and techniques of chain referral sampling. Sociological Methods \& Research 1981; 10(2): 141-163. http://dx.doi. org/10.1177/004912418101000205

Instituto Brasileiro de Geografia e Estatística - IBGE. Sistema de Contas Nacionais: Brasil 2004-2008. IBGE; 2010. [cited 2013 mar. 16]. Avaliable from: http:// www.ibge.gov.br/home/presidencia/noticias/noticia_ impressao.php?id_noticia $=1746$.

Instituto de Pesquisa Econômica Aplicada - IPEADATA. População residente total. IPEADATA; 2010. [cited 2013 mar. 16]. Avaliable from: http://www.ipeadata.gov.br/.

Pereira D, Santos D, Vedoveto M, Guimarães J, Veríssimo A. Fatos Florestais da Amazônia 2010. Belém: IMAZON; 2010. 122 p.

Programa de Desenvolvimento das Nações Unidas - PNUD. Ranking do IDH-M dos municípios do Brasil. PNUD; 2000. [cited 2013 mar. 18]. Avaliable from: http://www.pnud.org.br/atlas/tabelas/index.php.

Robert RCG, Santos AS, Santos LD, Fantini AC. Caracterização do abastecimento de madeira serrada comercializada no município de Florianópolis - SC. Floresta 2012; 42(1): 85-94.

Schuch C, Siminski A, Fantini AC. Usos e potencial madeireiro do jacatirão-açu (Miconia cinnamomifolia (de candolle) Naudin) no litoral de Santa Catarina. Floresta 2008; 38(4): 735-741.

Serviço Florestal Brasileiro - SFB. Florestas do Brasil em resumo 2010. Brasília: SFB; 2010. 143 p.

Silva RF. Diagnóstico das espécies mais utilizadas e alternativas para utilização nas serrarias localizadas na regional do baixo Acre [dissertação]. Rio Branco: Universidade Federal do Acre; 2002. 108 p.

Simioni FJ, Santos AJ. Aspectos da política florestal de Santa Catarina. Brasil Florestal 2004; 79: 25-31.

Simioni FJ, Hoff DN. Fatores críticos à produção florestal em Santa Catarina: um estudo de prospecção. In: Anais do $44^{\circ}$ Congresso da Sociedade Brasileira de Economia e Sociologia Rural; 2006; Fortaleza. Fortaleza: Soc. Bras. de Economia, Administração e Sociologia Rural; 2006. p. 277.

Vale RS, Macedo RLG, Venturin N, Mori FA, Morais AR. Efeito da desrama artificial na qualidade da madeira de clones de Eucalipto em sistema agrossilvipastoril. Revista Árvore 2002; 26(3): 285-297. http://dx.doi. org/10.1590/S0100-67622002000300004 